Review

\title{
Molecular mechanism of insulin resistance
}

\author{
Samir Bhattacharya ${ }^{1, *}$, Debleena Dey and Sib Sankar Roy \\ Molecular Endocrinology Laboratory, Indian Institute of Chemical Biology, 4, Raja S C Mullick Road, \\ Kolkata 700032, India \\ ${ }^{1}$ Cellular and Molecular Endocrinology Laboratory, Department of Zoology, School of Life Science, Visva-Bharati \\ (A Central University), Santiniketan 731 235, India \\ ${ }^{1}$ Corresponding author (Fax.91-3463-261268; Email, smrbhattacharya@yahoo.co.in)
}

\begin{abstract}
Free fatty acids are known to play a key role in promoting loss of insulin sensitivity, thereby causing insulin resistance and type 2 diabetes. However, the underlying mechanism involved is still unclear. In searching for the cause of the mechanism, it has been found that palmitate inhibits insulin receptor (IR) gene expression, leading to a reduced amount of IR protein in insulin target cells. PDK1-independent phosphorylation of $\mathrm{PKC} \varepsilon$ causes this reduction in insulin receptor gene expression. One of the pathways through which fatty acid can induce insulin resistance in insulin target cells is suggested by these studies. We provide an overview of this important area, emphasizing the current status.
\end{abstract}

[Bhattacharya S, Dey D and Roy S S 2007 Molecular mechanism of insulin resistance; J. Biosci. 32 405-413]

\section{Introduction}

Diabetes is of two types. Type 1 or insulin-dependent diabetes mellitus (IDDM) is basically due to autoimmunemediated destruction of the pancreatic $\beta$ islets resulting in insulin deficiency. Patients with type 1 diabetes usually have to take exogenous insulin for survival and to prevent the development of ketoacidosis. Type 2 diabetes or non-insulin dependent diabetes mellitus (NIDDM) is characterized by insulin resistance and is usually associated with abnormal insulin secretion. Globally, more than $90-95 \%$ of cases of diabetes are of this kind, while type 1 accounts for only 3-5\% (Zimmet 1999; Zimmet et al 2001). The growing incidence of insulin resistance and type 2 diabetes is seriously threatening human health globally. At the dawn of the new millennium, when $\mathrm{WHO}$ announced that the world was facing an epidemic of type 2 diabetes, the major question that was confronting us is what really causes this insidious disease.
This review deals with the mechanisms related to type 2 diabetes. Numerous reports demonstrate that oversupply of lipids raises the circulating level of free fatty acid (FFA) and contributes to the development of type 2 diabetes (Boden 1997; Mc Garry 2001. The excess FFA is ultimately stored in non-adipose depots leading to increased intramyocellular lipids, which cause insulin resistance (Boden et al 2001; Kuhlmann 2003). Initiation of insulin resistance or loss of insulin activity is the primary expression of this disease.

Although it is now fairly well established that FFAs are the major players effecting insulin resistance, the underlying mechanism by which this happens is still unclear. Inhibition of glucose transport by FFA has been found to be linked to insulin-mediated signals. Binding of insulin to the heterotetrameric membrane receptor results in insulin receptor substrate-1 (IRS-1) phosphorylation and IRS-1associated phosphatidylinositol 3 phosphate kinase (PI3 kinase) activation (Dresner et al 1999; Yu et al 2002; Chavez et al 2003). This affects downstream effectors such as Akt/

Keywords. Fatty acid; insulin receptor; insulin resistance, insulin signalling; novel PKC; type 2 diabetes

Abbreviations used: IDDM, insulin-dependent diabetes mellitus; NIDDM, non-insulin dependent diabetes mellitus; IR, insulin receptor; FFA, free fatty acid; IRS, insulin receptor substrate; PI3 kinase, phosphatidylinositol 3 phosphate kinase; PIP ${ }_{2}$, phosphatidylinositol 4,5 bisphosphate, DAG; diacylglycerol; PDK1, phosphoinositide-dependent kinase-1. 
PKB which activates the glucose transporter Glut4; Glut4 is then translocated to the membrane and imports glucose into the cell (Kohn et al 1996; Tanti et al 1997; Hill et al 1999). This suggests that the impairment of insulin activity leading to insulin resistance is linked to insulin signalling defects. Insulin signalling molecules involved in metabolic and mitogenic action may also play a role in cellular insulin resistance (Zick 2001; White 2002; Greene et al 2004). A few recent reports indicate that some PKC isoforms may have a regulatory effect on insulin signalling. The expression levels and activity of a few PKC isoforms are found to be associated with insulin resistance. Lipid infusion in rats and humans impairs insulin-stimulated glucose disposal in muscle concomitantly with the activation of certain PKC isoforms (Griffin et al 1999; Yu et al 2002; Boden and Shulman 2002). We have recently demonstrated that FFA-induced insulin resistance is linked to insulin receptor gene downregulation, in which a PKC isoform plays a significant role (Dey et al 2005). Although much progress has been made in understanding the mechanism of FFAinduced insulin resistance and type 2 diabetes, several lacunae exist in this important field. In this review we briefly describe these lacunae along with the current status of the problem.

\section{Insulin receptor and signalling}

The action of insulin is initiated through its binding with the target cell surface receptor that activates tyrosine kinase, a constituent of the receptor molecule. The insulin receptor (IR) is a heterotetramer consisting of two $\alpha$ subunits and two $\beta$ subunits that are linked by disulphide bonds into an $\alpha_{1} \alpha_{2}$ and $\beta_{1} \beta_{2}$ heterotetrameric complex. Insulin binds to the extracellular $\alpha$ subunit and transduces signals across the plasma membrane, which activates the intracellular tyrosine kinase $\mathrm{C}$ terminal domain of the $\beta$ subunit. Binding of insulin to IR effects a series of intramolecular transphosphorylation reactions, where one $\beta$ subunit phosphorylates its adjacent partner on a specific tyrosine residue (Pessin and Saltiel 2000). Although IRs are present on the surface of virtually all cells, their expression in classical insulin target tissues, i.e. muscle, liver and fat, is extremely high (Brunetti et al 2001). However, there is very little information on the regulatory mechanism that controls the IR at the level of gene expression. Autophosphorylation of the IR tyrosine residue stimulates the catalytic activity of receptor tyrosine kinase which recruits IRS proteins (IRS-1 and IRS-2) (Rosen 1987; Pessin and Saltiel 2000). These, in turn, augment the activity of the effector enzyme (Yenush et al 1998; White

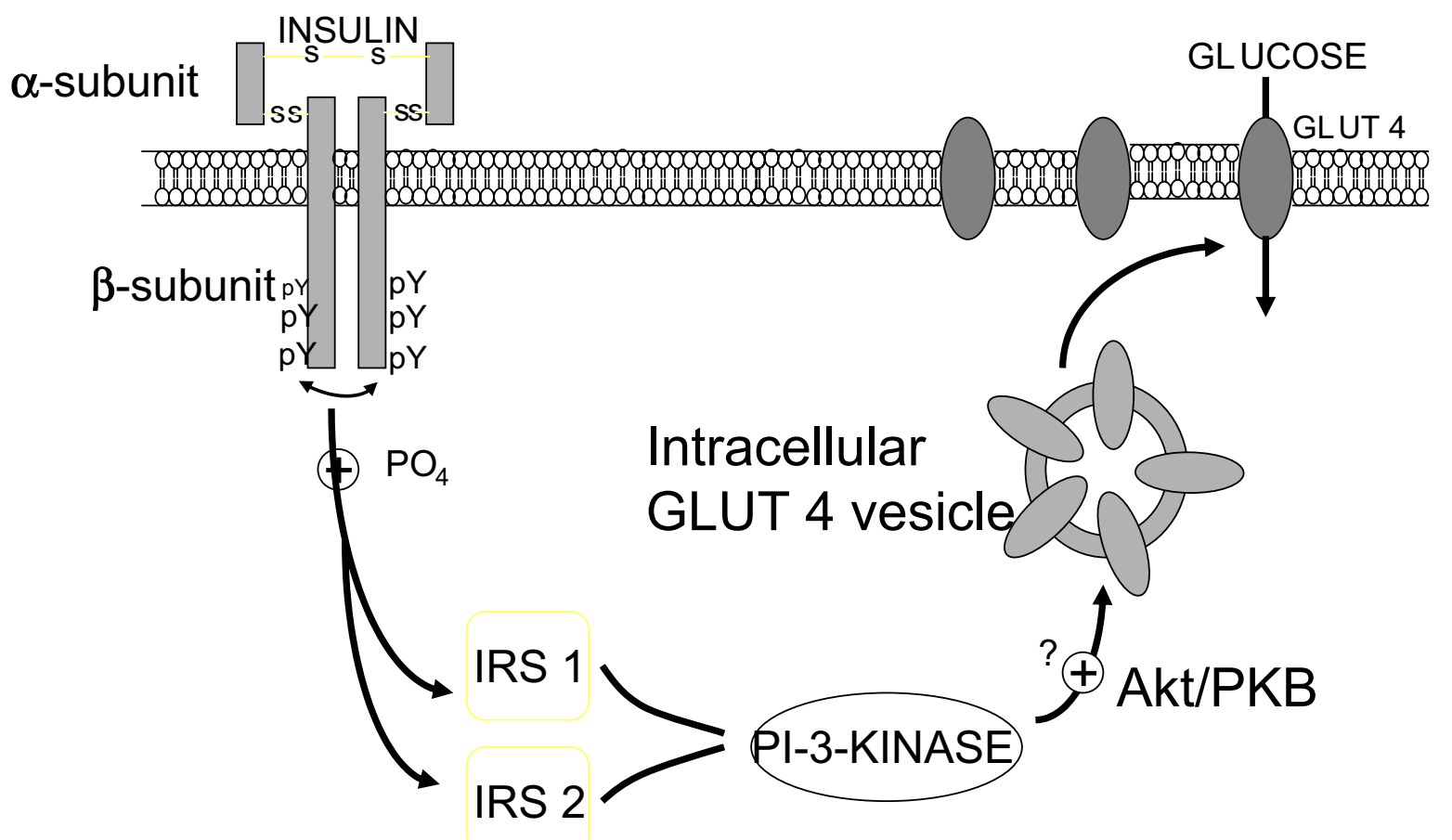

Figure 1. Insulin signalling pathway showing binding of insulin with the IR leading to activation of Glut4 which imports glucose into the cell. Activated insulin receptor tyrosine kinase phosphorylates IRS and PI3 kinase. PI3 kinase produces PI4,5 $\mathrm{P}_{2}$ and PI3,4,5 $\mathrm{P}_{3}$. These serve as docking sites for two ser/thr kinase PH domains, i.e. PDK1 and Akt/PKB. Binding of Akt/PKB to PIP3 activates Glut4. Activated Glut4 is translocated to the plasma membrane to transport glucose into the cell. 
1998). PI3 kinase is a target of the IRS proteins (IRS-1 and IRS-2) which phosphorylates specific phosphoinositides to form phosphatidylinositol 4,5 bisphosphate $\left(\mathrm{PIP}_{2}\right)$ to phosphatidylinositol 3,4,5 triphosphate; in turn, this activates ser/thr kinase, i.e. phosphoinositide-dependent kinase-1 (PDK1) (LeGood et al 1998). Activated PDK1 phosphorylates or activates ser/thr kinase Akt/PKB. Akt contains a PH domain that also interacts directly with PIP3 (Saltiel and Kahn 2001). Akt plays an important role by linking Glut4, the insulin-dependent glucose transporter protein, to the insulin signalling pathway. It activates Glut4 which moves to the cell surface to transport glucose into the cell (Pessin et al 1999; Kupriyonova and Kendror 1999; Martin et al 2000). Figure 1 briefly describes the insulin signalling pathway operative in the insulin target cell.

\section{FFA-induced impairment of insulin signalling}

Insulin has 3 major target tissues-skeletal muscle, adipose tissue and liver. Not only is the IR overexpressed in the cells of these tissues but these are also the three places where glucose is deposited and stored; no other cells can store glucose. In normal subjects the blood glucose level normally ranges between 90 and $120 \mathrm{mg} / \mathrm{dl}$; after a meal this may go up to $250-300 \mathrm{mg} / \mathrm{dl}$. The fasting insulin level remains at $15 \mu \mathrm{U} / \mathrm{ml}$ and after the intake of food it may go up to $40 \mu \mathrm{U} /$ $\mathrm{ml}$. This increase in insulin secretion is responsible for the post-prandial decrease in glucose which reaches the normal level after about 2 hours. Removal of this excess glucose by insulin occurs due to glucose uptake and storage in insulin target cells such as skeletal muscle cells, hepatocytes and adipocytes. About $75 \%$ of this glucose is stored in skeletal muscle cells; therefore, it is the major target cell of insulin, while the rest is stored in the liver and adipocytes. When an increase in insulin after a meal cannot take care of this process, the higher glucose in the circulation remains for a longer period, as occurs in type 2 diabetes. Patients suffering from insulin resistance and type 2 diabetes frequently display signs of abnormal lipid metabolism, increased circulatory concentration and elevated deposition of lipids in the skeletal muscle (Boden 1997; Mc Garry 2001). Increase in plasma lipid levels impairs insulin activity, increase in plasma FFA reduces insulin-stimulated glucose uptake, whereas a decrease in lipid content improves insulin activity in the skeletal muscle cells, adipocytes and liver (Moller 2001).

One of the sites that appears to be involved in fatty acidinduced insulin resistance is the IR itself. There are different ways by which fatty acids could impose insulin resistance. These are changes in IR expression, binding of ligands, the phosphorylation state of its kinase domain and the activity of receptor tyrosine kinases could account for insulin resistance. It could be a functional defect or may be related to genetic defects in the IR that influences its expression, binding to ligands and tyrosine kinase activity (Pessin and Saltiel 2000). Interesting results are obtained by studying IRs in knockout mice. Homozygous IR-null mice die shortly after birth owing to extreme insulin resistance (Accili et al 1996; Joshi et al 1996). IRS-1 is an important protein and homozygous knockout mice lacking a single allele of this gene lack any significant phenotype, whereas homozygous disruption of the IRS-1 gene results in a mild form of insulin resistance (Araki et al 1994). IRS-1 homozygous null mice $\left(\right.$ IRS-1 ${ }^{-/}$) do not show a clear diabetic phenotypic expression, presumably because of pancreatic $\beta$ cell compensation. However, mice that are doubly heterozygous $\left(\mathrm{IR}^{-1+}, \mathrm{IRS}^{-/+}\right)$ develop both insulin resistance and diabetes (Bruning et al 1997). Homozygous disruption of the IRS-2 gene, on the other hand, causes impairment of insulin secretion along with peripheral insulin resistance and diabetes (Withers et al 1998). The insulin resistance observed in IRS-2 knockout animals probably reflects secondary events due to alteration in $\beta$ cell function as IRS-2 appears to be unnecessary for insulin or exercise-stimulated glucose transport (Higaki et al 1999). This observation is consistent with the results of studies in $\beta$ cell-specific IR knockout mice, which develop peripheral insulin resistance and diabetes, most probably due to the changes in the pattern of insulin secretion (Kulkarni et al 1999).

FFA also affects downstream insulin signalling molecules. It inhibits insulin activation of IRS-1-associated PI3K activity in muscle. Reduction of insulin-stimulated IRS-1 tyrosine phosphorylation and IRS-1-associated PI3K activity by FFA has been shown to be associated with an increase in IRS-1 serine phosphorylation. This in turn decreases IRS-1 tyrosine phosphorylation, impairing down stream effectors (Yu et al 2002). FFA can disrupt further downstream insulin signals. Administration of saturated fat blocks insulin activation of Akt/PKB with a concomitant increase in the amount of ceramide and diacylglyerol in cultured muscle cells (Chavez et al 2003). Insulin actively sequesters Glut4 at an intracellular location which increases the rate of Glut4 trafficking to the membrane (Martin et al 2000). Glut4 is the penultimate molecule in the signal and its translocation to the membrane by insulin is the ultimate step in signalling, as only then is glucose transported into the cell. Lipid-associated insulin resistance has also been shown to be linked to Glut4 translocation defects (Pessin et al 1999).

\section{Mechanism of insulin resistance}

From the above description it is clear that FFAs induce defects in the insulin signalling pathway. However, the underlying mechanism of FFA-induced impairment of insulin signals is still unclear. Does FFA cause a defect in the IR leading to reduced efficiency in formation of the insulin-IR complex, or does it indirectly regulate IR activity which adversely 
affects downstream signalling molecules? Is the effect of FFA localized to a number of signalling points? These questions have not been answered. It has been suggested that insulin signalling molecules involved in the metabolic action of insulin also play a role in cellular signalling (Zick 2001; White 2002; Greene et al 2004). Some of the PKC isoforms represent such signalling molecules. PKC isoforms are classified as classical ( $\mathrm{cPKC} \alpha, \beta \mathrm{I}, \beta \mathrm{II}, \gamma)$, novel (nPKC $\delta, \varepsilon, \theta, \eta)$ and atypical (aPKC $\zeta, \lambda$ ). cPKCs are activated by $\mathrm{Ca}^{+2}$ and diacylglycerol (DAG), nPKCs are activated by only DAG and aPKCs respond to neither $\mathrm{Ca}^{+2}$ nor DAG (Newton 2003). Among all these PKC isoforms, nPKCs are said to have a modulatory role in insulin signalling. Recent reports also demonstrate a link between nPKCs and FFAinduced insulin resistance. Lipid infusion in rats and humans impaired insulin-stimulated glucose disposal into the muscle and concomitant activation of $\mathrm{PKC} \theta$ and $\mathrm{PKC} \delta$ (Boden and Shulman 2002; Itani et al 2002; Yu et al 2002). PKC $\delta$ has been shown to be a possible candidate for phosphorylation of the IR on serine residues, which obviously decreases tyrosine phosphorylation of the IR and affects its routing (Strack et al 1997). PKC $\delta$ has been shown to be regulating the state of IR phosphorylation (Kellerer 1997). Overexpression of $\mathrm{PKC} \delta$ in cultured myotubes stimulates serine phosphorylation of the IR in response to insulin. Since tyrosine phosphorylation of IR is the requirement to initiate the insulin signal, phosphorylation of serine would reduce insulin signalling efficiency. Overexpression of $\mathrm{PKC} \delta$ in cultured myotubes stimulates serine phosphorylation of IR in response to insulin. Serine phosphorylation of IR changes IR distribution on the cell membrane; a rich component of it is localized on the internal membrane instead of extracellular domain thus causing attenuation of insulin-induced tyrosine phosphorylation of the IR (Braiman et al 2001). These result in defects in the insulin signalling pathway imposing insulin resistance. Interestingly, activation of $\mathrm{PKC} \delta$ and PKC $\theta$ occurs along with FFA-induced insulin resistance in muscle cells (Boden and Shulman 2002). Suppression of endogenous glucose production in the liver by insulin is effectively inhibited by FFA with concomitant activation of PKC. What is still not clear is the mechanism involved in $\mathrm{PKC} \delta$-mediated inhibition of IR activity and whether it is direct or indirect. One report demonstrated that $\mathrm{PKC} \delta$ can directly inhibit IR kinase-stimulated IRS-1 associated tyrosine phosphorylation (Greene et al 2004). This has also been suggested to occur due to lipid-induced PKC $\theta$ activation in muscle (Schmitz-Peiffer et al 1997; Griffin et al 1999). We have recently shown that $\mathrm{PKC} \delta$ phosphorylation by insulin is further augmented by an FFA in 3T3L1 adipocyte cells and this is associated with the inhibition of insulin-stimulated IR $\beta$ and IRS-1 tyrosine phosphorylation (Dey et al 2006). The results of these studies promise some understanding of the occurrence of FFA-induced insulin resistance. However, the precise pathway by which FFA induces impairment of signalling molecules leading to insulin resistance still remains unclear.

\section{FFA-induced activation of $\mathrm{PKC} \varepsilon$ is linked to inhibition of $I R$ gene expression}

Clearly, the IR is one of the major targets in FFA-induced impairment of insulin activity. It is true that the molecular mechanism of insulin resistance is sufficiently complex. At the cellular level, it may occur at multiple steps of the insulin signalling pathway. Recent reports convincingly indicate that $\mathrm{nPKCs}$, i.e. $\mathrm{PKC} \delta, \mathrm{PKC} \theta$ and $\mathrm{PKC} \varepsilon$ implement FFA-induced insulin resistance, which is closely associated with the attenuation of IR activity (Itani et al 2002; Boden and Shulman 2002; Greene et al 2004). However, a clear link between FFA-induced nPKC activation and impairment of the IR has not been demonstrated. Recent evidence has shown that PDK1 can directly phosphorylate all PKCs including nPKCs (Toker and Newton 2000). PDK1 is the key upstream kinase in the insulin signalling pathway and all PKCs and Akt activation are known to be dependent on it (Alessi et al 1997; Newton 2003). Phosphorylated Akt then activates Glut4, which moves to the membrane to import glucose.

The $\mathrm{PKC} \varepsilon$ isotype has recently been shown to be related to insulin resistance. Translocation of $\mathrm{PKC} \varepsilon$ into the membrane is necessary for its phosphorylation by PDK1. $\mathrm{PKC} \varepsilon$ is overexpressed in the skeletal muscle of diabetic animals and humans, and its association with the plasma membrane causes its activation. This overexpression and activation of $\mathrm{PKC} \varepsilon$ leads to the downregulation of IR copy number on the cell membrane along with a decrease in Akt activity (Ikeda et al 2001; Itani et al 2002). Although these reports are interesting as they implicate a novel pathway of insulin resistance and diabetes, the underlying mechanism involved in $\mathrm{PKC} \varepsilon$-mediated insulin resistance has not yet been elucidated. We have recently shown a possible relationship between FFA-induced $\mathrm{PKC} \varepsilon$ phosphorylation and concomitant downregulation of IR. To understand the mechanism, we selected adipocytes and skeletal muscle cells from rat as well as respective cell lines. We observed that insulin stimulation of PDK1 phosphorylation is inhibited by an FFA, i.e. palmitate. PKC $\varepsilon$ phosphorylation is dependent on PDK1; FFA incubation of skeletal muscle cells and adipocytes inhibited PDK1 phosphorylation but surprisingly increased $\mathrm{PKC} \varepsilon$ phosphorylation. Inhibition of PDK1 by FFA is reflected in Akt phosphorylation as Akt phosphorylation is also dependent on PDK1 (figure 2). These results are conflicting as FFA is expected to increase the DAG content in a cell, which would influence PKC $\varepsilon$ localization towards the cell membrane (Stahelin et al 2005) and PDK1 would phosphorylate $\mathrm{PKC} \varepsilon$ since it is a 


\section{FFA induced PDK1 independent phosphorylation of PKC $\varepsilon$}

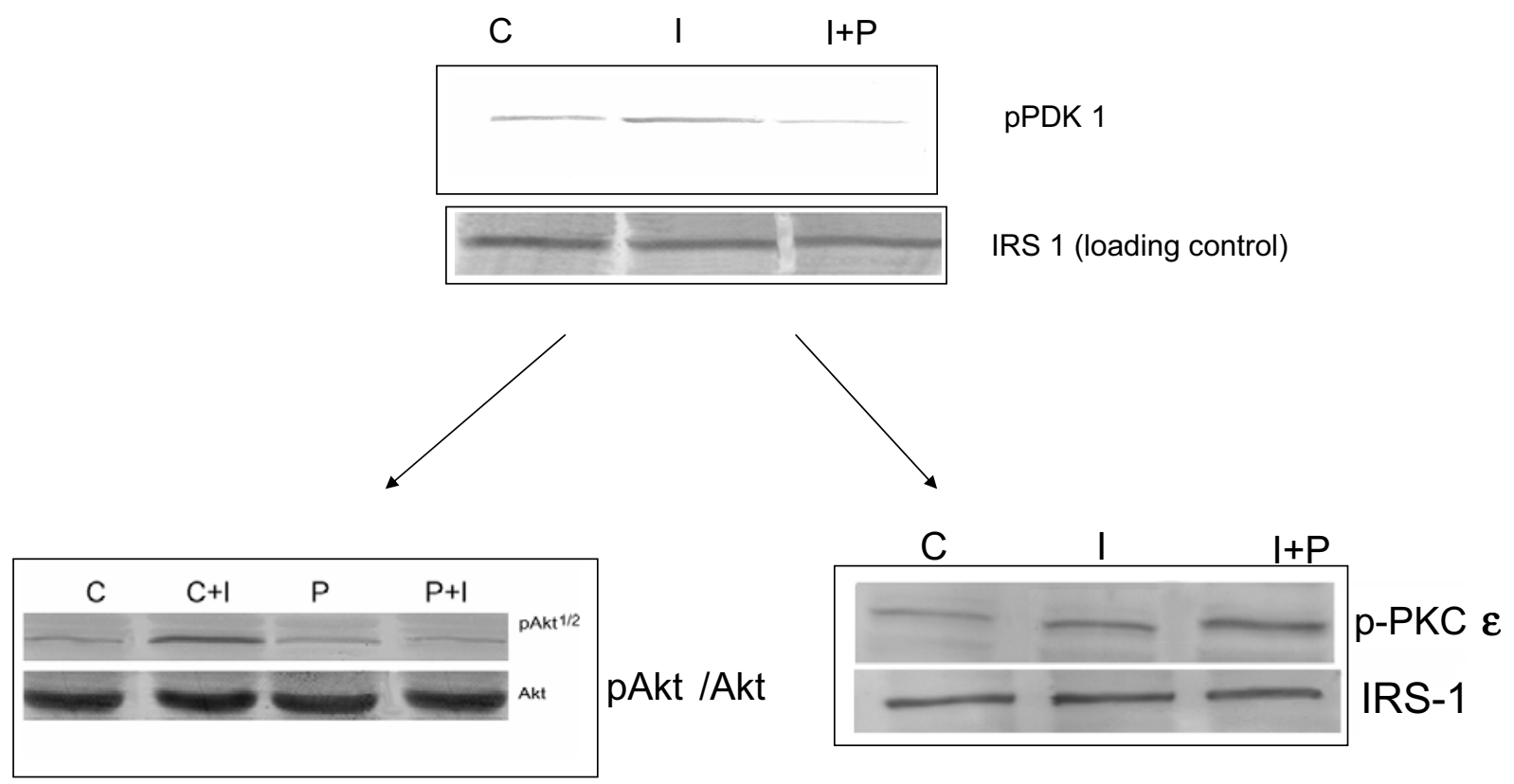

Figure 2. Effect of FFA on insulin-stimulated downstream signal, PDK1, Akt and PKC $\varepsilon$. Skeletal muscle cells were treated without or with palmitate for $8 \mathrm{~h}$ and insulin was added to both control (I) and palmitate (I+P) incubated cells. Cells without any of the treatments were taken as control (C). On termination of incubation, cells were lysed by sonication and $50 \mu \mathrm{g}$ protein from each cell lysate was resolved in $10 \%$ SDS-PAGE and then subjected to Western blot analysis with anti-pPDK1, pAkt/Akt or anti-pPKC $\varepsilon$ antibodies (1:1000). (Dey et al 2005).

PDK1-dependent PKC isoform. This is the known pathway of $\mathrm{nPKC}$ phosphorylation by PDK1; on the contrary, $\mathrm{PKC} \varepsilon$ showed PDK1-independent phosphorylation due to FFA (Dey et al 2005; Dey et al 2006). We could not understand how PDK1-independent phosphorylation of PKC $\varepsilon$ could occur due to FFA. This remained a mystery until we came across an interesting report describing constitutive phosphorylation of $\mathrm{PKC} \varepsilon$ by FFA in a PDK1-independent manner. This report showed that myristic acid incubation of HEPG2 cells causes myristoylation of $\mathrm{PKC} \varepsilon$ which results in constitutive phosphorylation of $\mathrm{PKC} \varepsilon$ at thr566/ser729 in the kinase domain required for $\mathrm{PKC} \varepsilon$ activity. This phosphorylation was totally independent of PDK1, which the workers demonstrated by using PDK1 knockout cells. This PDK1-independent phosphorylation of PKC $\varepsilon$ could not be further increased by co-transfecting the $P D K 1$ gene, or decreased with kinase-inactive PDK1 transfection (Cenni et al 2002). In the same way, addition of palmitate to skeletal muscle cells or adipocytes may affect palmitoylation of $\mathrm{PKC} \varepsilon$ resulting in constitutive phosphorylation of $\mathrm{PKC} \varepsilon$ (Dey et al 2005; Dey et al 2006). We also found that activation of $\mathrm{PKC} \varepsilon$ is inversely related to IR gene expression, palmitate decreases IR mRNA in a time-dependent manner, while inhibitors of phosphoPKC $\varepsilon$ block this decrease. Palmitate activation of $\mathrm{PKC} \varepsilon$ occurs at $2 \mathrm{~h}$ in the plasma membrane. At $6 \mathrm{~h}$ most of the phosphorylated $\mathrm{PKC} \varepsilon$ is associated with the nuclear fraction indicating translocation of $\mathrm{pPKC} \varepsilon$ from cytosol to the nuclear region. This appears to be related to the inhibition of IR gene transcription. Considerable inhibition of IR gene transcription occurs at 6 $\mathrm{h}$ (Dey et al 2005). Taken together, it is clear that FFA causes PDK1-independent phosphorylation of $\mathrm{PKC} \varepsilon$ which in turn translocates to the nucleus, and its time of entry into the nucleus coincides with inhibition of IR gene transcription. This would obviously reduce the copies of IR protein on the insulin target cell membrane. However, it is still unclear how $\mathrm{pPKC} \varepsilon$ reduces IR gene expression on entering the nucleus.

\section{Molecular mechanism of FFA-induced inhibition of IR gene transcription}

The IR is usually expressed at low levels in all cell types except in classical insulin target tissues, i.e. skeletal muscle, liver and fat, where IR is expressed at a very high level (Goldfine 1987). Many workers have suspected that the IR is the major 
component responsible for the loss of insulin sensitivity or insulin resistance. A few earlier reports indicate that the IR is of major importance in certain states of insulin resistance in humans, where qualitative and quantitative abnormalities of the receptor may cause defects in transmembrane signalling (Taylor 1992; Polonsky et al 1996; Taylor 1999; Virkamaki et al 1999). However, very little is known about the regulatory mechanism controlling gene expression of the IR. To understand the molecular basis of regulation of IR gene expression, the promoter region of the human IR gene has been identified and studied by several groups (Mitchell and Tjian 1989; Seino et al 1989; Lee et al 1992). The IR promoter region extends over 1800 bases upstream from the IR gene ATG codon and is extremely GC rich. It contains a series of GGGCGG repeats that are putative binding sites for the mammalian transcription factor SP1 (Mitchell and Tjian 1989). It lacks a TATA box or consensus initiator sequence and includes multiple transcription initiator sites within the first $300 \mathrm{bp} \mathrm{GC-rich} \mathrm{region.} \mathrm{Two} \mathrm{unique} \mathrm{AT-rich} \mathrm{sequences,}$ $\mathrm{C} 2$ and E3, within the IR gene promoter have been identified and both these sequences are positively regulated by the architectural transcription factor HMGA1 (earlier known as HMG1-Y), a member of the high mobility group protein family (Brunetti et al 2001). HMGA1 interacts with the ATrich regions in the minor groove of DNA through highly conserved DNA-binding peptide motifs termed AT hooks, and regulates transcriptional activation of many genes by modifying DNA conformation, which permits recruitment of transcriptional factor to the transcription start site (Bustin and Reeves 1996; Reeves 2001). HMGA1 protein has the ability to bind to DNA packaged in nucleosomes and regulates the expression of a number of genes through their migration from the heterochromatin to euchromatin region (Reeves et al 2000; Reeves 2001; Reeves and Beckerbauer 2001). It has been shown that inhibition of HMGA1 in cells that naturally express high IR levels significantly reduces cell surface expression of IR. Inversely, cells with relatively low IR content, when transfected with HMGA1, show IR overexpression and a significant increases in IR protein expression (Brunetti et al 2001). All these indicate that HMGA1 plays an important role in regulating transcription of the IR gene. The same group of workers has recently

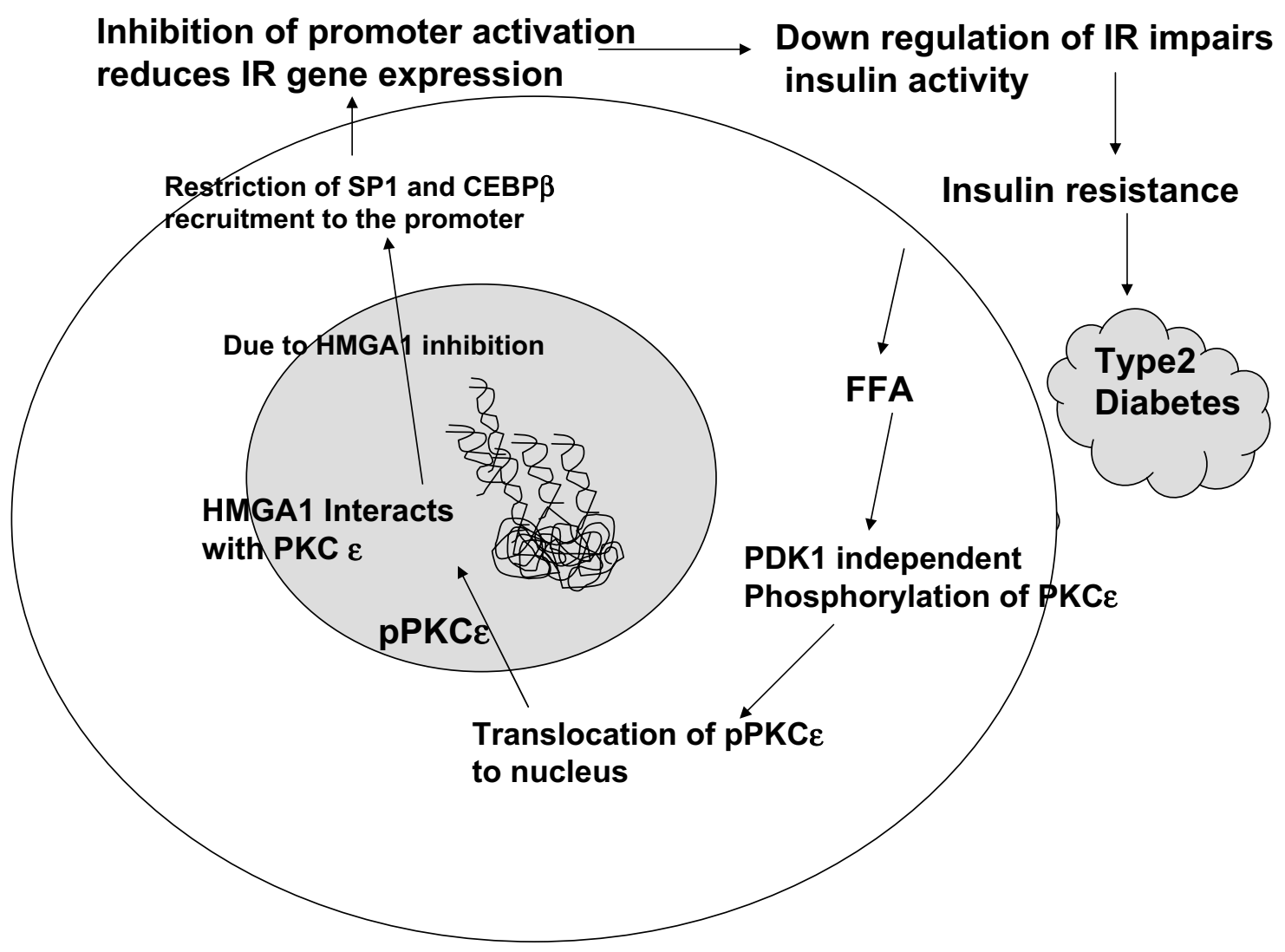

Figure 3. Schematic representation of the mechanism involved in insulin resistance. Excess of lipid mobilization to the major insulin target cells effects constitutive phosphorylation of $\mathrm{PKC} \varepsilon$, and that translocates to the nuclear region and reduces IR promoter activation. Inhibition in HMGA1 gene expression restricts recruitment of SP1 and CEBP $\beta$ to the IR promoter causing inhibition of promoter activation leading to downregulation of insulin receptor gene expression. 
shown that HMGA1 induces transcriptional activation of the human IR gene by permitting the recruitment of SP1 and $\operatorname{cEBP} \beta$, the ubiquitously expressed transcription factors, to the promoter region. HMGA1 plays the role of an architectural transcription factor here as mutational interference of the HMGA1 binding site in the IR promoter abolished its binding, which adversely affected recruitment of SP1 and $\operatorname{cEBP} \beta$ to the IR promoter, resulting in inhibition of IR promoter activation (Foti et al 2003).

A recent report demonstrates that a genetic flaw which reduces the intracellular expression of HMGA1 protein can adversely affect IR expression in cells and tissues from subjects with insulin resistance and type 2 diabetes (Foti et al 2005). There could be another aspect in the regulation of IR gene expression involving HMGA1. We have demonstrated that FFA-induced downregulation of the IR gene is associated with PDK1-independent constitutive phosphorylation of $\mathrm{PKC} \varepsilon$ in major insulin target cells. Phospho PKC $\varepsilon$ is translocated to the nucleus which causes inhibition of IR gene expression. But how phosphorylated $\mathrm{PKC} \varepsilon(\mathrm{pPKC} \varepsilon)$ downregulates the IR gene is unclear. Further work using PKC inhibitors showed that their administration along with FFA could block inhibition of IR gene expression (Dey et al 2005; Dey et al 2006). The question is how is $\mathrm{pPKC} \varepsilon$ related to the regulation of IR gene expression. There is a possibility that activated $\mathrm{PKC} \varepsilon$ phosphorylates HMGA1 which inhibits HMGA1 mobilization to the promoter region IR gene. It has been shown that phosphorylation of HMGA1 protein reduces its DNA-binding ability (Reeves and Beckerbauer 2001). Phosphorylated HMGA1 protein would preferentially interact with positively charged histones as there would be an additional negative charge, while dephosphorylated HMGA1 proteins are expected to interact with negatively charged DNA (Harrer et al 2004). Since HMGA1 proteins are highly mobile and this mobility is finely tuned, hyper- and hypophosphorylation of these could be the major factors in regulating the expression of the IR gene. Without the mobilization of HMGA1 to the IR promoter there is no recruitment of transcription factor to the promoter region of the IR gene and therefore no expression of the IR gene.

Although it is well established that FFA is responsible for insulin resistance as its increase in the milieu of major insulin-sensitive cells causes insulin resistance by reducing insulin sensitivity, the molecular mechanism involved is largely unknown. This review focuses on the current trends in research in this important domain and throws light on certain possibilities regarding the manner in which FFA inhibits insulin activity. The available information suggests that the IR is one of the most important sites identified so far for loss of insulin sensitivity. Figure 3 schematically represents the present status of knowledge in this field. Excess of lipid mobilization to the major insulin target cells will effect constitutive phosphorylation of $\mathrm{PKC} \varepsilon$, which when translocated to the nuclear region somehow reduces IR promoter activation. Inhibition of $H M G A 1$ gene expression in diabetic patients has recently been demonstrated, but how this is linked to FFA is unclear. However, there may be a possibility that FFA-induced $\mathrm{pPKC} \varepsilon$ might play a role in this particular area.

\section{Acknowledgements}

We gratefully acknowledge the help of Dr Anirban Bhattacharya and Dr Dipanjan Basu in the preparation of this review.

\section{References}

Accili D, Drago J, Lee E J, Johnson M D, Cool M H, Salvatore P, Asico L D, Jose PA, Taylor S I and Westphal H 1996 Early neonatal death in mice homozygous for a null allele of the insulin receptor gene; Nat. Genet. 12 106-109

Alessi D R, Deak M, Casamayor A, Caudwell F B, Morrice N, Norman D G, Gaffney P, Reese C B, MacDougall C N, Harbison D, Ashworth A and Bownes M 1997 3-Phosphoinositidedependent protein kinase-1 (PDK1): structural and functional homology with the Drosophila DSTPK61kinase; Curr. Biol. 7 776-789

Araki E, Shimada F, Uzawa H, Mori M and Ebina Y 1987 Characterization of the promoter region of the human insulin receptor gene; J. Biol. Chem. 262 16186-16191

Boden G 1997 Role of fatty acids in the pathogenesis of insulin resistance and NIDDM; Diabetes 46 3-10

Boden G, Chen X, Capulong E and Mozzoli M 2001 Effects of free fatty acids on gluconeogenesis and autoregulation of glucose production in type 2 diabetes; Diabetes $\mathbf{5 0} 810-816$

Boden G and Shulman G I 2002 Free fatty acids in obesity and type 2 diabetes: defining their role in the development of insulin resistance and beta-cell dysfunction; Eur. J. Clin. Invest. 32 Suppl. 3 14-23

Braiman L, Alt A, Kuroki T, Ohba M, Bak A, Tennenbaum T and Sampson SR 2001 Insulin induces specific interaction between insulin receptor and protein kinase $\mathrm{C}$ delta in primary cultured skeletal muscle; Mol. Endocrinol. 15 565-574

Brunetti A, Manfioletti G, Chiefari E, Goldfine I D and Foti D 2001 Transcriptional regulation of human insulin receptor gene by the high-mobility group protein HMGI(Y); FASEB J. 15 492-500

Bruning J C, Winnay J, Cheatham B and Kahn C R1997 Differential signaling by insulin receptor substrate 1 (IRS-1) and IRS-2 in IRS-1-deficient cells; Mol. Cell Biol. 17 1513-1521

Bustin M and Reeves R 1996 High-mobility-group chromosomal proteins: architectural components that facilitate chromatin function; Prog. Nucleic Acids Res. Mol. Biol. 54 35-100

Cenni V, Doppler H, Sonnemburg E D, Maraldi N, Newton A C and Toker A 2002 Regulation of novel protein kinase $\mathrm{C}$ epsilon by phosphorylation; Biochem. J. 363 537-545 
Chavez J A, Knotts T A, Wang L P, Li G, Dobrowsky R T, Florant G L and Summers S A 2003 A role for ceramide, but not diacylglycerol, in the antagonism of insulin signal transduction by saturated fatty acids; J. Biol. Chem. 278 10297-10303

Dey D, Basu D, Roy S S, Bandyopadhyay A and Bhattacharya S 2006 Involvement of novel PKC isoforms in FFA induced defects in insulin signaling; Mol. Cell. Endocrinol. 26 60-64

Dey D, Mukherjee M, Basu D, Datta M, Roy S S, Bandyopadhyay A and Bhattacharya S 2005 Inhibition of insulin receptor gene expression and insulin signaling by fatty acid: interplay of PKC isoforms therein; Cell. Physiol. Biochem. 16 217-228

Dresner A, Laurent D, Marcucci M, Griffin M E, Dufour S, Cline G W, Slezak L A, Andersen D K, Hundal R S, Rothman D L, Petersen K F and Shulman G I 1999 Effects of free fatty acids on glucose transport and IRS-1-associated phosphatidylinositol 3-kinase activity; J. Clin. Invest. 103 253-259

Foti D, Iuliano R, Chiefari E and Brunetti A 2003 A nucleoprotein complex containing Sp1, C/EBP $\beta$, and HMGI-Y controls human insulin receptor gene transcription; Mol. Cell. Biol. 23 $2720-2732$

Foti D, Chiefari E, Fedeli M, Iuliano R, Brunetti L, Paonessa F, Manfioletti G, Barbetti F, Brunetti A, Croce M C, Fusco A and Brunetti A 2005 Lack of the architectural factor HMGA1 causes insulin resistance and diabetes in humans and mice; Nat. Med. $11765-773$

Goldfine I D 1987 The insulin receptor: molecular biology and transmembrane signalling; Endocrinol. Rev. 8 235-255

Greene M W, Morrice N, Garofalo R S and Roth R A 2004 Modulation of human receptor substrate 1 tyrosine phosphorylation by protein kinase C $\delta$; Biochem. J. 378 105-116

Griffin M E, Marcucci M J, Cline G W Bell K, Barucci N, Lee D, Goodyear L J, Kraegen E W, White M F and Shulman G I 1999 Free fatty acid-induced insulin resistance is associated with activation of protein kinase $\mathrm{C}$ theta and alterations in the insulin signaling cascade; Diabetes 48 1270-1274

Harrer M, Luhrs H, Bustin M, Scheer U and Hock R 2004 Dynamic interaction of HMGAla proteins with chromatin; J. Cell. Sci. $1173459-3471$

Higaki Y, Wojtaszewski J F, Hirshman M F, Withers D J, Towery H, White M F and Goodyear L J 1999 Insulin receptor substrate2 is not necessary for insulin- and exercise-stimulated glucose transport in skeletal muscle; J. Biol. Chem. 274 20791-20795

Hill M M, Clark S F, Tucker D F, Birnbaum M J, James D E, and Macaulay S L 1999 A role of protein kinase B $\beta /$ Akt2 in insulin stimulated Glut4 translocation in adipocyte;s Mol. Cell. Biol. 19 7771-7781

Ikeda Y, Olsen G S, Ziv E, Hansen L L, Busch A K, Hansen Bo F, Shafrir E and Mostaf-Seedorf L 2001 Cellular mechanism of nutritionally induced insulin resistance in Psammomys obesus; Diabetes 50 584-592

Itani S I, Ruderman N B, Frank S and Boden G 2002 Lipid induced insulin resistance in human muscle is associated with changes in diacylglycerol, protein kinase C, and Ikb- $\alpha$; Diabetes $\mathbf{5 1}$ 2005-2011

Joshi R L, Lamothe B, Cordonnier N, Mesbah K, Monthioux E, Jami J and Bucchini D 1996 Targeted disruption of the insulin receptor gene in the mouse results in neonatal lethality; $E M B O$ J. 15 1542-1547
Kellerer M, Mushack J, Mischak H, Häring H U 1997 Protein kinase $\mathrm{C}$ (PKC) epsilon enhances the inhibitory effect of TNF alpha on insulin signaling in HEK293 cells; FEBS Lett. 418 119-122

Kohn A D, Summers S A, Birnbaum M J and Roth R A 1996 Expression of a constitutively active Akt Ser/Thr kinase in 3T3 L1 adipocytes stimulates glucose uptake and glucose transporter 4 translocation; J. Biol. Chem. 271 31372-31378

Kuhlmann J, Neumann-Haefelin C, Belz U, Kalisch J, Juretschke H P, Stein M, Kleinschmidt E, Kramer W and Herling A W 2003 Intramyocellular lipid and insulin resistance: a longitudinal in vivo $1 \mathrm{H}$-spectroscopic study in Zucker diabetic fatty rats; Diabetes 52 138-144

Kulkarni R N, Bruning J C, Winnay J N, Postic C, Magnuson M A and Kahn C R 1999 Tissue-specific knockout of the insulin receptor in pancreatic beta cells creates an insulin secretory defect similar to that in type 2 diabetes; Cell 96 329-339

Kupriyanova T A and Kandror K V 1999 Akt-2 binds to Glut4containing vesicles and phosphorylates their component proteins in response to insulin; J. Biol. Chem. 274 1458-1464

Le Good J A, Ziegler W H, Parekh D B, Alessi D R, Cohen P and Parker P J 1998 Protein kinase C isotypes controlled by phosphoinositide 3-kinase through the protein kinase PDK1; Science 281 2042-2045

Lee J K, Tam J W O, Tsai M J and Tsai S Y 1992 Identification of cis- and trans-acting factors regulating the expression of the human insulin receptor gene; J. Biol. Chem. $2674638-4645$

Martin S, Millar C A, Lyttle C T, Meerloo T, Marsh B J, Gould G W and James D E 2000 Effects of insulin on intracellular GLUT4 vesicles in adipocytes: evidence for a secretory mode of regulation; J. Cell Sci. 113 3427-3438

McGarry 2001 Banting lecture. Dysregulation of fatty acid metabolism in the etiology of type 2 diabetes; Diabetes 51 7-18

Mitchell P J and Tjian R 1989 Transcriptional regulation in mammalian cells by sequence-specific DNA binding proteins; Science 245 371-378

Moller D E 2001 New drug targets for type 2 diabetes and the metabolic syndrome; Nature (London) 414 821-827

Newton A C 2003 Regulation of the ABC kinases by phosphorylation: protein kinase $\mathrm{C}$ as a paradigm; Biochem. J. 370 361-371

Pessin J E and Saltiel A R 2000 Signaling pathways in insulin action: molecular targets of insulin resistance; J. Clin. Invest. 106 165-169

Pessin J E, Thurmond D C, Elmendorf J S, Coker K J and Okada S 1999 Molecular basis of insulin-stimulated GLUT4 vesicle trafficking; J. Biol. Chem. 274 2593-2596

Polonsky K S, Sturis J and Bell G I 1996 Non-insulin-dependent diabetes mellitus: a genetically programmed failure of the beta cell to compensate for insulin resistance; N. Engl. J. Med. 334 777-783

Reeves R and Beckerbaur L: $2001 \mathrm{HMG}$ 1/Y proteins: flexible regulators of transcription and chromatin structure; Biochim. Biophys. Acta. Mol. Cell Res. 1519 13-29

Reeves R 2000 Structure and function of the HMGI(Y) family of architectural transcription factors; Environ. Health Perspect. 108 803-809

Reeves R 2001 Molecular biology of HMGA proteins: hubs of nuclear function; Gene 277 63-81

Rosen O M 1987 After insulin binds; Science 237 1452-1458 
Saltiel A R and Kahn C R 2001 Insulin signalling and the regulation of glucose and lipid metabolism; Nature 414 799-806

Schmitz-Peiffer C, Browne C L, Oakes N D, Watkinson A, Chisholm D J, Kraegen E W and Biden T J 1997 Alterations in the expression and cellular localization of protein kinase $\mathrm{C}$ isozymes $\varepsilon$ and $\theta$ are associated with insulin resistance in skeletal muscle of the high-fat-fed rat; Diabetes 46 169-178

Seino S, Seino M, Nishi S and Bell G I 1989 Structure of the human insulin receptor gene and characterization of its promoter; Proc. Natl. Acad. Sci. USA 86 114-118

Stahelin R V, Digman M A, Medkova M, Ananthanarayanan B, Melowic H R, Rafter J D and Cho W 2005 Diacylglycerolinduced membrane targeting and activation of protein kinase C epsilon: mechanistic differences between PKC delta and epsilon; J. Biol. Chem. 280 19784-19793

Strack V, Stoyanov B, Bossenmaier B, Mosthaf L, Kellerer M and Haring H U 1997 Impact of mutations at different serine residues on the tyrosine kinase activity of the insulin receptor; Biochem. Biophys. Res. Commun. 239 235-239

Tanti J F, Grillo S, Gremeaux T, Coffer P J, Van Obbberghen E, Le Marchand and Brustel Y 1997 Potential role of protein kinase $\mathrm{B}$ in glucose transporter 4 translocation in adipocytes; Endocrinology 138 2005-2010

Taylor S I 1992 Lilly lecture: molecular mechanisms of insulin resistance. Lesson from patients with mutations in the insulinreceptor gene; Diabetes 411473-1490

Taylor S I 1999 Deconstructing type 2 diabetes; Cell 97 9-12

Toker A and Newton A C 2000 Cellular signaling: pivoting around PDK-1; Cell 103 185-188
Virkamäki A, Ueki K, Kahn C R 1999 Protein-protein interaction in insulin signaling and the molecular mechanisms of insulin resistance; J. Clin. Invest. 103 931-943

White M F 2002 IRS proteins and the common path to diabetes; Am. J. Physiol. Endocrinol. Metab. 283 E413-E422

White M F 1998 The IRS-signalling system: a network of docking proteins that mediate insulin action; Mol. Cell. Biochem. 182 $3-11$

Withers D J, Gutierrez J S, Towery H, Burks D J, Ren J M, Previs S, Zhang Y, Bernal D, Pons S, Shulman G I, Bonner-Weir S and White M F 1998 Disruption of IRS-2 causes type 2 diabetes in mice; Nature (London) 391 900-904

Yenush L, Zanella C, Yuchida C, Bernal D and White M F 1998 The pleckstrin homology and phosphotyrosine binding domains of insulin receptor substrate 1 mediate inhibition of apoptosis by insulin; Mol. Cell. Biol. 18 6784-6794

Yu C, Chen Y, Cline G W, Zhang D, Zong H, Wang Y, Bergeron R, Kim J K, Cushman S W, Cooney G J, Atcheson B, White M F, Kraegen E W and Shulman GI 2002 Mechanisms by which fatty acids inhibit insulin activation of insulin receptor substrate-1 (IRS-1)-associated phosphatidylinositol 3-kinase activity in muscle; J. Biol. Chem. 27 50230-50236

Zick Y 2001 Insulin resistance: a phosphorylation-based uncoupling of insulin signaling; Trends Cell Biol. 11 437-441

Zimmet P Z 1999 Diabetes epidemiology as a tool to trigger diabetes research and care; Diabetologia 42 499-518

Zimmet P, Alberti K G and Shaw J 2001 Global and societal implications of the diabetes epidemic; Nature (London) 414 782-787

MS received 8 October 2006; accepted 28 November 2006

ePublication: 9 February 2007

Corresponding editor: HYUK B KWON 